\title{
Novel formulation and evaluation of a Q I0-loaded solid lipid nanoparticle cream: in vitro and in vivo studies
}

This article was published in the following Dove Press journal:

International Journal of Nanomedicine

29 March 201 I

Number of times this article has been viewed

Effat Sadat Farboud

Saman Ahmad Nasrollahi

Zahra Tabbakhi

Department of Pharmaceutics, School of Pharmacy, Tehran University of Medical Sciences, Tehran, Iran
Correspondence: Effat Sadat Farboud School of Pharmacy, Tehran University of Medical Sciences, Tehran, Iran

Tel +98 2I 64122217

Fax +98 2I 6646 II 78

Email farbod@sina.tums.ac.ir

\begin{abstract}
Solid lipid nanoparticles (SLNs) of coenzyme Q10 (CoQ10) were formulated by a high-pressure homogenization method. The best formulation of SLN dispersion consisted of 13\% lipid (cetyl palmitate or stearic acid), 8\% surfactant (Tween 80 or Tego Care 450), and water. Stability tests, particle size analysis, differential scanning calorimetry, transmission electron microscopy, and release study were conducted to find the best formulation. A simple cream of CoQ10 and a cream containing CoQ10-loaded SLNs were prepared and compared on volunteers aged 20-30 years. SLNs with particle size between $50 \mathrm{~nm}$ and100 nm exhibited the most suitable stability. In vitro release profiles of CoQ10 from simple cream, SLN alone, and CoQ10-loaded SLN cream showed prolonged release for SLNs compared with the simple cream, whereas there was no significant difference between SLN alone and SLN in cream. In vitro release studies also demonstrated that CoQ10-loaded SLN and SLN cream possessed a biphasic release pattern in comparison with simple cream. In vivo skin hydration and elasticity studies on 25 volunteers suggested good dermal penetration and useful activity of Q10 on skin as a hydratant and antiwrinkle cream.
\end{abstract}

Keywords: coenzyme Q10, SLN, release study

\section{Introduction}

Coenzyme Q10 (CoQ10) is a naturally occurring, lipid-soluble, and chemically unstable compound that is synthesized by mammals and plants and serves as a potent antioxidant. CoQ10 has been reported to have beneficial effects on the heart, lungs, liver, and skin. ${ }^{1,2}$ It has been shown that by lowering matrix metalloproteinase levels in fibroblasts, CoQ10 reduces wrinkles. ${ }^{3}$ CoQ10 also exerts anti-inflammatory effects on dermal fibroblasts. ${ }^{4}$ In a clinical study, application of $1 \%$ Q10 cream for 5 months effectively reduced wrinkle score grade. ${ }^{3}$ The level of Q10 in skin declines with age and ultraviolet (UV) irradiation. In skin, the epidermis contains 10-fold higher Q10 than does the dermis. ${ }^{5}$ The epidermis as the most outer layer of the skin is directly exposed to UV irradiation and other environmental factors, which makes it susceptible to depletion of skin antioxidants such as Q10; ${ }^{6}$ therefore, the epidermis may represent a tissue that presumably benefits most from topically applied Q10. ${ }^{3}$ CoQ10 can retard loss of hyaluronic acid and slowdown of cell division, both of which are manifestations of intrinsic aging. According to the in vitro data, aged human fibroblasts produce less glycosaminoglycan and proliferate more slowly than do young cells. The addition of Q10 increases levels of glycosaminoglycan as well as rates of cell division. ${ }^{7}$

Solid lipid nanoparticles (SLNs) have been introduced as a potent carrier system for various pharmaceutical and cosmetic active compounds. They are capable of 
protecting unstable active compounds against degradation, ${ }^{8}$ releasing the active ingredients in a controlled way ${ }^{9}$ and prolonging residence time of some actives such as sunscreens in the stratum corneum, ${ }^{10}$ as well as targeting drug to the upper layer of skin. ${ }^{11}$ They also show occlusive properties in vitro and decrease water evaporation from the skin to the atmosphere. ${ }^{12,13}$ Occlusion promotes the penetration of actives into the skin. Due to the reduced water loss caused by occlusion, skin hydration is increased after dermal application of SLN or SLN-containing formulations. In a comparative study, the SLN-containing oil-in-water $(\mathrm{o} / \mathrm{w})$ cream increased the skin hydration significantly more than did conventional o/w cream. ${ }^{14}$ Increased penetration of CoQ10 was described after application of Q10-loaded SLN suspension in comparison with solutions of isopropanol and liquid paraffin. ${ }^{15,16}$

SLNs represent a highly effective carrier for cosmetic creams that are intended to increase skin hydration. It was shown that incorporation of CoQ10 into an SLN matrix also provides good chemical stability, so we decided to add CoQ10 to SLNs. In order to evaluate the release pattern, SLN dispersions were further processed to o/W creams to mimic professional use in cosmetics and were evaluated both in vitro and in vivo. The aim of the in vivo study was the investigation of the effect of loading Q10 in the form of SLNs compared with the simple form by measuring hydration and elasticity of skin.

\section{Material and methods Materials}

Compritol 888ATO (glyceryl behenate), Precifac ATO (cetyl palmitate), and Labrasol (PEG-8 caprylic/capric triglycerols) were purchased from Gattefosse (Cedex, France). Tego Care 450 (polyglyceryl-3 methylglucose distearate) was obtained from Goldschmidt (Essen, Germany). Stearyl alcohol, cetyl alcohol, isopropyl myristate, stearic acid, beeswax, spermaceti, Tween 20, Tween 80, Span 60, and sorbitan monooleate were purchased from Merck (Germany). CoQ10 was from Sigma-Aldrich (St. Louis, MO, USA), and all other chemicals were analytical reagent grade.

\section{Methods}

\section{Preparation of solid lipid nanoparticles}

The lipid phase was melted and the drug was dispersed in the lipid melt to obtain a clear solution. The dispersion medium (ie, distilled water with surfactants) was heated to the temperature of the lipid melt. The hot lipid phase was dispersed in a surfactant solution by high-speed stirring using Ultra-Turrax T25 (IKA-Werke, Staufen, Germany). The dispersion was then subjected to high-pressure homogenization using IKA HPH (2000/4 SH5, Germany). The obtained nanodispersion was allowed to cool down to room temperature, forming lipid nanoparticles by recrystalization of the dispersed lipid. ${ }^{9}$ Different lipids, including beeswax, spermaceti, Comperitol 888, cetyl alcohol, stearyl alcohol, stearic acid, and cetyl palmitate, were tested. We used Tween 80, Tween 20, and Tego Care 450 as our surfactants.

\section{Preparation of oil/water cream}

Both the lipid and aqueous phases of the cosmetic cream were heated separately to $75^{\circ} \mathrm{C}$. Hot water was then added to the lipid phase with stirring. The resulting emulsion cooled down to $40^{\circ} \mathrm{C}$ and the drug (CoQ10) was added. Under constant stirring, the o/w cream cooled down to ambient temperature. ${ }^{9}$ For the SLN-containing cream, 50\% of the SLN dispersion containing Q10 (with a double concentration of Q10) was mixed with half of the o/w cream.

\section{Particle size analysis and zeta potential measurement}

The particle size of SLN dispersions was analyzed using photon correlation spectroscopy (PCS) based on the manufacturer's instructions (Zetasizer 4, Malvern Instruments, Herrenberg, Germany).

\section{Thermal analysis of SLN dispersions}

Differential scanning calorimetry (DSC) studies were performed using a Mettler DSC 821e.The DSC measurements were carried out on the following samples: unloaded SLN, CoQ10, Q10-loaded SLN (both as lyophilized powder forms), and stearic acid as a lipid phase in SLN formulation. Each sample (1-3 mg) was transferred into a $40 \mu \mathrm{L}$ aluminum container, and an empty standard aluminum pan was used as reference. The samples were heated from $25^{\circ} \mathrm{C}$ to $85^{\circ} \mathrm{C}$ and subsequently cooled down to $0^{\circ} \mathrm{C}$ at a rate of $5^{\circ} \mathrm{C} / \mathrm{min}$ while flushing with nitrogen $(80 \mathrm{~mL} / \mathrm{min})$. Each experiment was carried out in triplicate.

\section{Transmission electron microscopy}

Transmission electron microscopy (TEM) was performed at the Faculty of Science using HU-12A (Hitachi Ltd, Mito, Japan). One drop of nanoparticle dispersion (aqueous solution of SLN) was placed on the copper grid and then negatively stained with one drop of $2 \%$ (weight/volume) aqueous solution of phosphotungstrate acid for contrast enhancement. The samples were allowed to dry before examination under the TEM. 


\section{In vitro release study}

An automated, temperature-controlled continuous flow through diffusion cells (six cells) was used to evaluate the amount of drug released from the developed formulations. The diffusion cells (surface area $0.64 \mathrm{~cm}^{2}$ ) were thermoregulated with a water jacket at $37^{\circ} \mathrm{C}$. Cellulose nitrate membrane filters were soaked with water and mounted to diffusion cells. Aqueous solution of 5\% labrasol was used as a receptor fluid and passed through the receptor chamber at a controlled rate using a multichannel peristaltic pump. One milliliter of samples (Q10-loaded SLN cream, Q10 simple cream, Q10loaded SLN) was applied to the donor compartment. Samples were collected over 7 hours and analyzed by HPLC according to the method of Teeranachaideekul et al. ${ }^{17}$

\section{In vivo skin hydration and viscoelasticity studies \\ Corneometer measurement}

Skin hydration was investigated using a corneometer, which was mounted on a multiprobe adapter. Capacitance changes depending almost solely on the water content in the stratum corneum were detected and evaluated. Three measurements were performed in each testing area on the forehead. The results are given in arbitrary units. Statistical evaluation was performed by Student's $t$-test.

\section{Cutometer measurement}

The viscoelastic properties of the skin were investigated with a cutometer (Dermalab ${ }^{\circledR}$, Cortex, Denmark). The measuring principle is suction/elongation ratio. Each measurement consisted of three suction cycles ( 3 seconds of suction followed by 3 seconds of relaxation) and was performed in triplicate on the forehead. The absolute parameter and the relative parameter were evaluated as reference.

\section{Skin $\mathrm{pH}$ measurement}

The skin $\mathrm{pH}$ of subjects before and after a 2-month period of using the creams was measured by a pH-meter (Dermalab ${ }^{\circledR}$, Cortex, Denmark).

\section{Study design}

The study was designed as double-blind research. Twentyfive healthy females (average age $22 \pm 2$ years) with healthy skin who signed informed consent forms used one of the test formulations: formulation A (Q10 simple cream) or formulation B (Q10-loaded SLN cream). They were asked not to wear any other moisturizer or antiaging products on their face 1 week before and during the clinical trial. They had to use the cream once every 24 hours at night on their face. The skin properties were measured on day 0 (basic value, prior to application of the creams) and after 30 and 60 days. On days 30 and 60 , the creams were not applied prior to the measurements. The study was approved by the Ethics Committee of Tehran University of Medical Sciences in accordance with the Helsinki Declaration and guidelines of the Iranian Ministry of Health and Medical Education.

\section{Statistics}

The data are presented as mean values \pm standard deviation. Significance of difference was evaluated using Student's $t$-test and Kolmogorov-Smirnov test at the probability level of 0.05 .

\section{Results and discussion Formulation optimization}

CoQ10 is practically insoluble in water and has high solubility in the lipid, so it was incorporated into the lipid phase of the SLN formulation. In order to optimize CoQ10-loaded SLN, different formulation variables such as type and concentration of surfactants and solid lipids were evaluated and the nanoparticle dispersions were characterized for physicochemical properties such as color and stability after storing at different temperatures $\left(4^{\circ} \mathrm{C}, 25^{\circ} \mathrm{C}\right.$, and $\left.40^{\circ} \mathrm{C}\right)$.

Table 1 shows formulations with different solid lipids ranging between $10 \%$ and $30 \%$ and a fixed amount of hydrophilic surfactant. The most stable formulation was selected for the next experiment.

Table 2 shows formulations with a fixed amount of solid lipid and a variable amount of surfactants. The selected formulation was determined based on the best results in stability, size, and appearance.

In the next step, the best formulation shown in Table 2 was made with different lipids, including beeswax, spermaceti, Comperitol 888, cetyl alcohol, stearyl alcohol, stearic acid, and cetyl palmitate. We used Tween 80, Tween 20, and Tego Care 450 as our surfactants. The percentages of ingredients were not changed.

Table I The best formulation of solid lipid nanoparticles when the percentage of solid lipid changes

\begin{tabular}{llll}
\hline & Ingredient & $\begin{array}{l}\text { Weight/weight } \\
\text { percentage }\end{array}$ & $\begin{array}{l}\text { The best } \\
\text { formulation }\end{array}$ \\
\hline Oil phase & Solid lipid & $10-30$ & 13 \\
& Coenzyme Q10 & 0.01 & 0.01 \\
\multirow{2}{*}{ Water phase } & Hydrophilic surfactant & 13 & 13 \\
& Distilled water & $57-77$ & 74 \\
\hline
\end{tabular}


Table 2 The best formulation of solid lipid nanoparticles when the percentage of surfactant changes

\begin{tabular}{llll}
\hline & Ingredient & $\begin{array}{l}\text { Weight/weight } \\
\text { percentage }\end{array}$ & $\begin{array}{l}\text { The best } \\
\text { formulation }\end{array}$ \\
\hline Oil phase & Solid lipid & 13 & 13 \\
& Coenzyme Q10 & 0.01 & 0.01 \\
\multirow{2}{*}{ Water phase } & Hydrophilic surfactant & $8-18$ & 8 \\
& Distilled water & $69-79$ & 79 \\
\hline
\end{tabular}

Based on our data shown in Table 3, the formulations containing stearic acid and cetyl palmitate as lipids had the most stability, smallest size, and best appearance. The measured zeta potentials for both SLNs indicated very good shelf life physical stability, and polydispersity index values were lower than 0.2 , suggesting a relatively narrow size distribution. ${ }^{17}$ Data for all of the formulated SLNs were not shown. The hydrophiliclipophilic balance value and the structure of surfactant have significant effects on formulation quality. Based on the results depicted in Table 3, we selected SLN2 as our best formulation, then the best formulation was incorporated into the cream base. Table 4 shows the ingredients of the cream base.

\section{The characterization of optimized SLNs}

\section{Stability study}

Not all of the SLNs exhibited good stability during storage. Some SLNs showed chemical or physical instabilities. The physical stability of the SLNs during prolonged storage was determined by monitoring changes in zeta potential, particle size, drug content, and appearance. Among those formulations prepared from different surfactants and lipids, the SLNs shown in Table 3 showed suitable physical and chemical stability during the 6-month period of the study. No obvious color change, degradation, or phase separation was observed. The mean diameter of Q10-loaded SLNs and the entrapment efficiency were measured at 50-100 $\mathrm{nm}$ and $99 \% \pm 0.5 \%$, respectively.

\section{Particle size analysis}

TEM of SLN dispersion of Q10 showed the spherical shape nanoparticles entrapping Q10. Figure 1 shows a monolayer coating of surfactant surrounding solid lipids. The TEM studies confirmed the observed particle size of SLNs ranging between $50 \mathrm{~nm}$ and $100 \mathrm{~nm}$.

To study the connection between lipid content and the achieved particle size, we measured the particle size of different formulations with variable amount of stearic acid and a fixed amount of Tween 80. As depicted in Figure 2, elevation of the lipid content of formulation increased the particle size of SLNs.

Due to desired physicochemical specifications, we also selected the formula SLN2 for our in vivo study.

\section{Thermal analysis}

We used DSC for detecting potential drug-excipient incompatibilities as well as melting and recrystallization behavior of crystalline materials like SLNs. As depicted in Figure 3, the DSC profiles of stearic acid as a solid lipid component of SLN formulation showed apparent endothermic peaks at about $63^{\circ} \mathrm{C}$. We detected the melting point of CoQ 10 at $54^{\circ} \mathrm{C}$. The profile of the lyophilized powder of Q10-loaded SLN showed a single peak around $57^{\circ} \mathrm{C}$, whereas the SLN without Q10 had an endothermic peak at $58^{\circ} \mathrm{C}$. The height of the endotherm in the thermogram of SLN-containing Q10 was less than that in SLN without Q10, suggesting loss of crystallinity of the lipids and Q10 after incorporation into SLN. ${ }^{9}$ During the production procedure, Q10 was dissolved in the melted lipid phase. Stearic acid showed one peak at $63^{\circ} \mathrm{C}$, indicating no polymorphic forms.

The peak of stearic acid in the formulation had a slight shift to the lower temperature side. This could be due to a reduction in particle size and an increase in surface area, leading to a decrease in melting enthalpy.

The results indicate that Q10 incorporated in SLN was not in a crystalline state but in an amorphous form. When the materials were formulated as SLN, the endothermic temperature was lower. Along with a certain effect of surfactants, the observed depressed endothermic peak for SLN may be due to the nanometric size of the particles with a huge surface area.

\section{In vitro release study}

As shown in Figures 4 and 5, the release of Q10 from SLN and SLN cream was faster than from simple cream. Due to the solid matrix of the nanoparticles and the subsequent drug

Table 3 The best formulations of solid lipid nanoparticles (SLNs) with suitable stability and particle size

\begin{tabular}{|c|c|c|c|c|c|c|c|}
\hline No. & Solid lipid & Surfactant & $\begin{array}{l}\text { Water } \\
\text { phase }\end{array}$ & $\begin{array}{l}\text { Active } \\
\text { ingredient }\end{array}$ & $\begin{array}{l}\text { Particle } \\
\text { size }(\mathrm{nm})\end{array}$ & $\begin{array}{l}\text { Zeta } \\
\text { potential }(\mathrm{mV})\end{array}$ & $\begin{array}{l}\text { Polydispersity } \\
\text { index }\end{array}$ \\
\hline SLNI & Cetyl palmitate & Tegocare 450 & Water & QI0 & $100 \pm 15$ & -44.4 & 0.203 \\
\hline SLN2 & Stearic Acid & Tween 80 & Water & Q10 & $50 \pm 10$ & -47.1 & 0.109 \\
\hline $\begin{array}{l}\text { Percentage } \\
\text { of above ingredients }\end{array}$ & 13 & 8 & 79 & 0.01 & & & \\
\hline
\end{tabular}


Table 4 Ingredients used in formulation of simple cream and cream containing solid lipid nanoparticles

\begin{tabular}{lll}
\hline & Solid lipid nanoparticle & Simple cream \\
\hline Oil phase & Stearic acid I3\% & $\begin{array}{l}\text { Cetyl alcohol I\% } \\
\text { Stearyl alcohol I\% } \\
\text { Cetyl palmitate I\% } \\
\text { Isopropyl myristate I0\% }\end{array}$ \\
& & Distilled water 82\% \\
Water phase & Distilled water 79\% & Tween 80 3.5\% \\
& Tween 80 8\% 60 I.5\% \\
Active ingredient & Coenzyme Q10 0.02\% & \\
\hline
\end{tabular}

immobilization, the release of encapsulated Q10 appeared different from that of Q10 cream. The PCS mean diameter of the SLN dispersion was $50 \mathrm{~nm}$, whereas it was about $1 \mu \mathrm{m}$ in the simple emulsion.

The percentage of released Q10 from simple cream was more than for SLN and SLN cream at the first hour time point, but after 7 hours it released only about $40 \%$ of Q10 contents, whereas SLN and SLN cream released almost all of the Q10 contents, which almost reflected what was reported by Teeranachaideekul et al. ${ }^{17}$ The initial release within the first 5 hours was faster for the SLN formulation than for the simple cream, which can be explained by enrichment of Q10 in the outer shell of the particles. The prolonged release in the second phase can be explained by slower diffusion of Q10 from the solid lipid of SLN. The solid lipid matrix creates a slow release pattern of Q10. The Q10 release from the cream formulation appeared to be slower than release from SLN and SLN cream, although it did not reach a significant level. It has been reported that chemical stability of Q10 increases after incorporation into lipid nanoparticles. ${ }^{18-20}$ The SLN cream has a higher viscosity compared with SLN alone, which slows down the release. In the simple cream, Q10 appeared to mix homogenously with the cream base, leading to an almost constant Q10 release, which could be explained by Fick's law of diffusion.

\section{In vivo study}

In order to avoid low viscosity of SLN dispersions, which makes them undesirable to apply on the skin, we incorporated
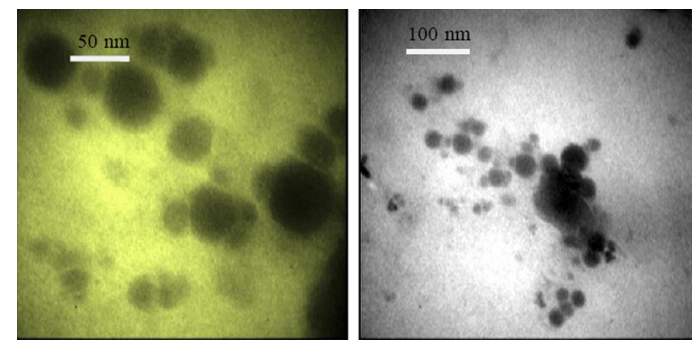

Figure I Transmission electron microscopy photograph of a Q I0-loaded solid lipid nanoparticle.

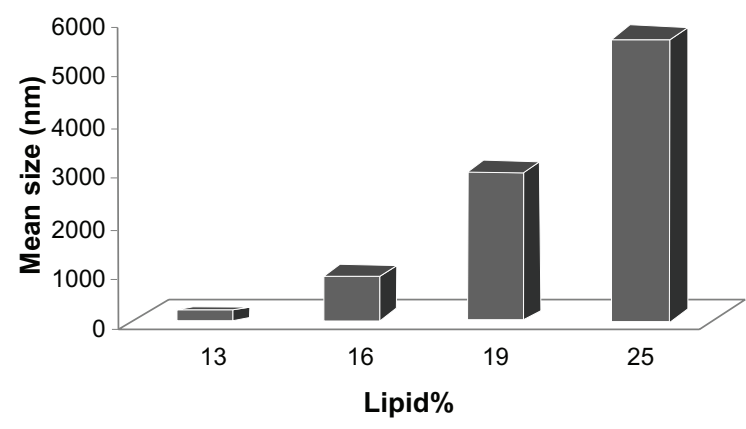

Figure 2 Elevation of lipid content in formulation increases the particle size.

the lipid dispersion into a cream base (Table 4). Our in vivo study was designed as a double-blind investigation and was conducted on 25 healthy females as described before.

After 1 month of topical application, both formulations showed an increase in skin humidity of $40 \%$ and $65 \%$ for simple cream and SLN cream, respectively. The elasticity of skin was also improved 5\% and $120 \%$ for simple cream and SLN cream users, respectively. Surprisingly, after 2 months, in simple cream users a $40 \%$ increase in skin humidity and $20 \%$ elasticity enhancement was observed, whereas in SLN cream users we detected a $120 \%$ and $125 \%$ increase in skin humidity and elasticity, respectively. The SLN cream profoundly increased both skin humidity and elasticity when compared with simple cream. The results are shown in Figures 6 and 7.

Improving skin hydration and elasticity may be due to the formation of a film on the skin and subsequent occlusive effect of the film. The occlusive effect of lipid nanoparticles has already been reported. ${ }^{14}$ The highest occlusion is achievable by using low melting lipids and very small particles, which in turn reduce water loss. The skin hydration effect is increased after dermal application of SLN-containing formulations. The o/w cream containing SLN drastically increased the skin hydration when it was compared with simple o/w cream.

The skin $\mathrm{pH}$ was slightly reduced after both SLN cream and simple cream applications, which might be due to the acidic nature of the formulation ingredients.

\section{Conclusion}

SLNs have been used as carrier for CoQ10 to protect it from degradation, releasing it in a controlled fashion and increasing the effectiveness of active ingredients. The data presented here clearly demonstrate that the formulations of SLN-containing stearic acid and cetyl palmitate as lipids achieved a high stability, small size, and good appearance. The collected zeta potentials for both of the SLNs indicated very good physical stability during the shelf life, and polydispersity index values were lower than 0.2 , indicating a relatively narrow size distribution. No obvious changes of 


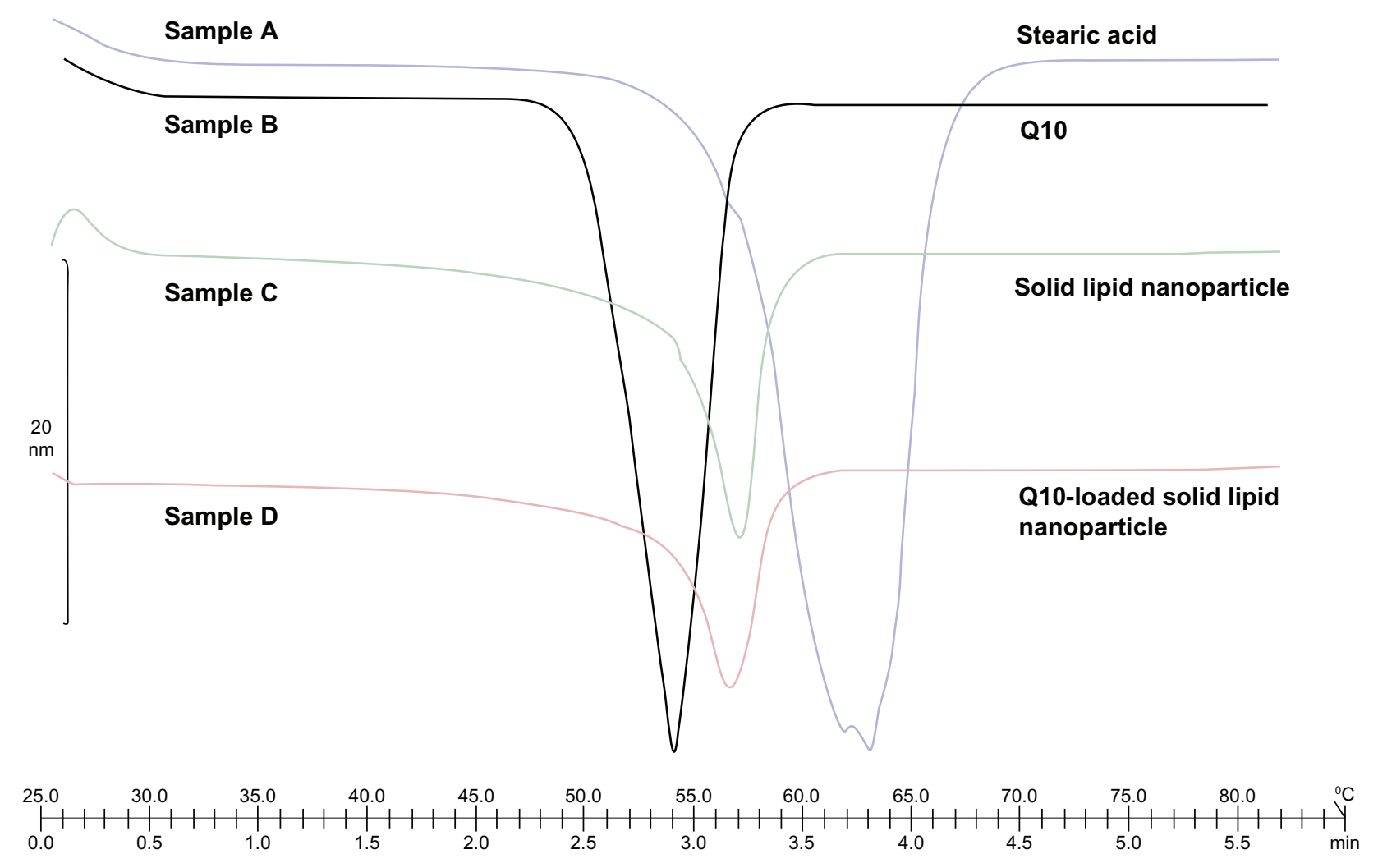

Figure 3 Differential scanning calorimetry thermogram of sample A (stearic acid), sample B (coenzyme QI0), sample C (solid lipid nanoparticle), and sample D (QI0-loaded solid lipid nanoparticle).

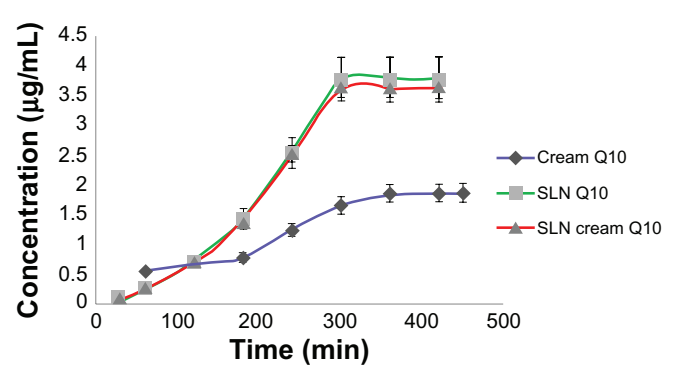

Figure 4 Concentration of released Q10 versus time for simple Q10, solid lipid nanoparticle (SLN), and QI0-loaded SLN cream.

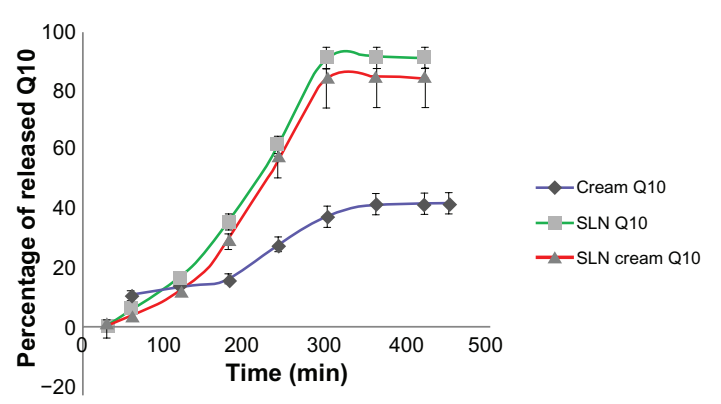

Figure 5 Percentage of released Q10 versus time for simple Q10, solid lipid nanoparticle (SLN), and QI0-loaded SLN cream.

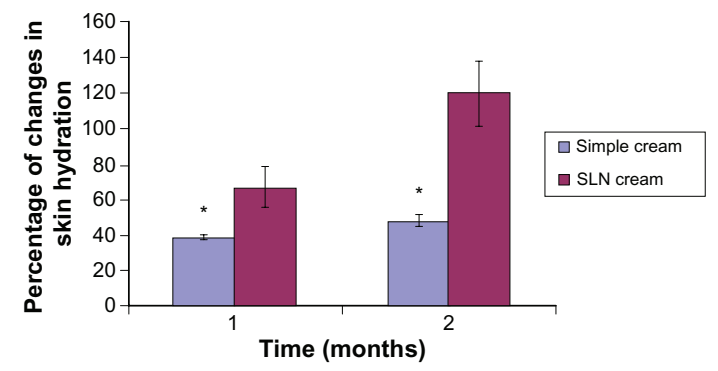

Figure 6 Percentage of increase in hydration for simple cream and solid lipid nanoparticle (SLN) cream containing Q10 after I- and 2-month application periods. All results are expressed as values related to the measured values on day 0 and the untreated control (mean \pm standard deviation, $\mathrm{n}=25 ; P<0.05$ ).

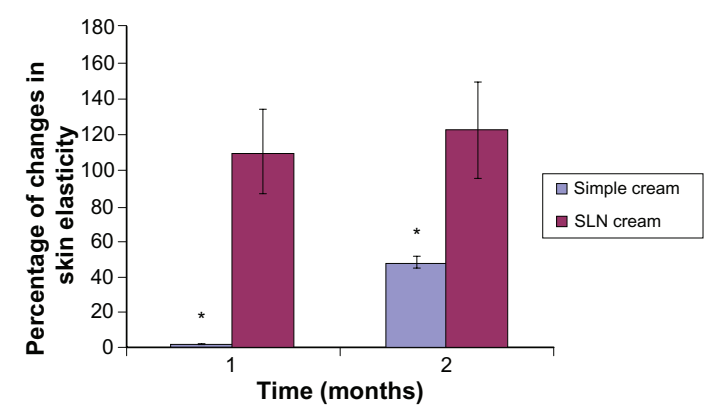

Figure 7 Percentage of increase in elasticity for simple and solid lipid nanoparticle (SLN) cream containing Q10 after I- and 2-month application periods. All results are expressed as values related to the measured values on day 0 and the untreated control (mean \pm standard deviation, $\mathrm{n}=25 ; P<0.05$ ). 


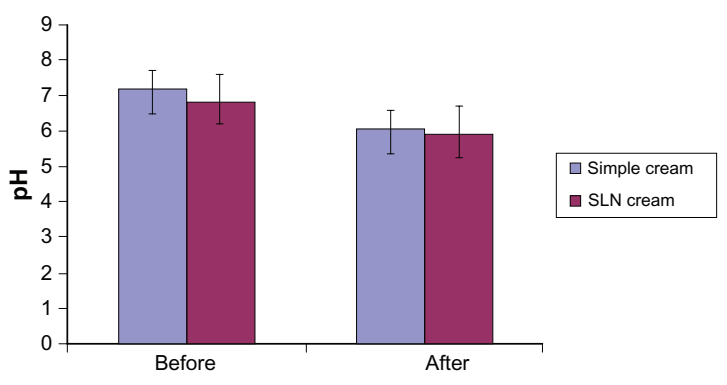

Figure 8 Changes in skin pH after using solid lipid nanoparticle (SLN) cream and simple cream (mean \pm standard deviation, $\mathrm{n}=25 ; P<0.05$ ).

color, degradation, or phase separation were observed. The mean diameter of Q10-loaded SLN was 50-100 nm and the entrapment efficiency was about $99 \% \pm 0.5 \%$. The TEM studies confirmed this particle size analysis. The results of DSC indicated that Q10 incorporated in SLN was not in a crystalline state but in an amorphous form. When the material was formulated as SLN, the endothermic temperature was lower. The depressed endothermic peak for SLN may be due to the nanometric size of the particles, which had a huge surface area in addition to a certain surfactant effect.

The initial release within the first 5 hours was faster for SLN formulation compared with the simple cream, which can be explained by enrichment of Q10 in the outer shell of the particles. The prolonged release in the second phase can be explained by slower diffusion of Q10 from the solid lipid of SLN. The solid lipid matrix creates a slow release pattern of Q10. Comparing the drug release from SLN and SLN cream, the release of Q10 was slower from the cream formulation, although it did not reach a significant level.

We also found that SLN cream increased skin humidity and elasticity much more than did simple cream. Skin hydration and elasticity enhancement is a desirable effect in dermal preparations, especially in antiwrinkle creams.

\section{Disclosure}

The authors report no conflicts of interest in this work.

\section{References}

1. Kocharian A, Shabanian R, Rafiei-Khorgami M, et al. Coenzyme Q10 improves diastolic function in children with idiopathic dilated cardiomyopathy. Cardiol Young. 2009;19(5):501-506.
2. Sohet FM, Neyrinck AM, Pachikian BD, et al. Coenzyme Q10 supplementation lowers hepatic oxidative stress and inflammation associated with diet-induced obesity in mice. Biochem Pharmacol. 2009;78(11):1391-1400.

3. Inui M, Ooe M, Fujii K, et al. Mechanisms of inhibitory effects of CoQ10 on UVB-induced wrinkle formation in vitro and in vivo. Biofactors. 2008;32(1-4):237-243.

4. Fuller B, Smith D, Howerton A, Kern D. Anti-inflammatory effects of CoQ10 and colorless carotenoids. J Cosmet Dermatol. 2006; 5(1):30-38.

5. Shindo Y, Witt E, Han D, et al. Enzymic and non-enzymic antioxidants in epidermis and dermis of human skin. J Invest Dermatol. 1994;102(1): 122-124.

6. Podda M, Traber MG, Weber C, et al. UV-irradiation depletes antioxidants and causes oxidative damage in a model of human skin. Free Radic Biol Med. 1998;24(1):55-65.

7. Hoppe U, Bergemann J, Diembeck W, et al. Coenzyme Q10, a cutaneous antioxidant and energizer. Biofactors. 1999;9(2-4): 371-378.

8. Jenning V, Gohla SH. Encapsulation of retinoids in solid lipid nanoparticles (SLN). J Microencapsul. 2001;18(2):149-158.

9. Jenning V, Schafer-Korting M, Gohla S. Vitamin A-loaded solid lipid nanoparticles for topical use: drug release properties. J Control Release. 2000;66(2-3):115-126.

10. Wissing SA, Muller RH. A novel sunscreen system based on tocopherol acetate incorporated into solid lipid nanoparticles. Int J Cosmet Sci. 2001;23(4):233-243.

11. Jenning V, Gysler A, Schafer-Korting M, Gohla SH. Vitamin A loaded solid lipid nanoparticles for topical use: occlusive properties and drug targeting to the upper skin. Eur J Pharm Biopharm. 2000;49(3): 211-218.

12. de Vringer T, inventor; Yamanouchi Europe B.V. (NL), assignee. Topical preparation containing a suspension of solid lipid particles. United States Patent US 5904932. 1999 May 18.

13. Mandawgade SD, Patravale VB. Development of SLNs from natural lipids: application to topical delivery of tretinoin. Int J Pharm. 2008;363(1-2): $132-138$.

14. Wissing SA, Muller RH. The influence of solid lipid nanoparticles on skin hydration and viscoelasticity - in vivo study. Eur J Pharm Biopharm. 2003;56(1):67-72.

15. Pardeike J, Hommoss A, Muller RH. Lipid nanoparticles (SLN, NLC) in cosmetic and pharmaceutical dermal products. Int $J$ Pharm. 2009;366(1-2):170-184.

16. Pardeike J, Müller RH. Coenzyme Q10-loaded NLCs: preparation, occlusive properties and penetration enhancement. Pharm Technol Eur. 2007;19:46-49.

17. Teeranachaideekul V, Souto EB, Junyaprasert VB, Muller RH. Cetyl palmitate-based NLC for topical delivery of Coenzyme Q(10) development, physicochemical characterization and in vitro release studies. Eur J Pharm Biopharm. 2007;67(1):141-148.

18. Dingler A, Blum RP, Niehus H, et al. Solid lipid nanoparticles (SLN/ Lipopearls) - a pharmaceutical and cosmetic carrier for the application of vitamin E in dermal products. J Microencapsul. 1999;16(6): 751-767.

19. Dingler A, Gohla S. Production of solid lipid nanoparticles (SLN): scaling up feasibilities. J Microencapsul. 2002;19(1):11-16.

20. Puglia C, Filosa R, Peduto A, et al. Evaluation of alternative strategies to optimize ketorolac transdermal delivery. AAPS PharmSciTech. 2006; 7(3):64.

International Journal of Nanomedicine

\section{Publish your work in this journal}

The International Journal of Nanomedicine is an international, peerreviewed journal focusing on the application of nanotechnology in diagnostics, therapeutics, and drug delivery systems throughout the biomedical field. This journal is indexed on PubMed Central, MedLine, CAS, SciSearch ${ }^{\circledR}$, Current Contents $\mathbb{\circledR} /$ Clinical Medicine,

\section{Dovepress}

Journal Citation Reports/Science Edition, EMBase, Scopus and the Elsevier Bibliographic databases. The manuscript management system is completely online and includes a very quick and fair peer-review system, which is all easy to use. Visit http://www.dovepress.com/ testimonials.php to read real quotes from published authors. 